\title{
World Parks Congress 2014: Parks, people and planet
}

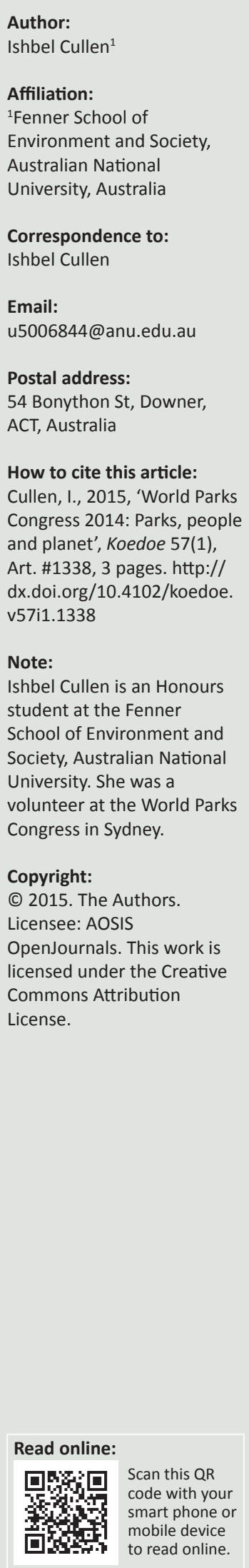

\section{Introduction}

The 6th International Union for Conservation of Nature (IUCN) World Parks Congress took place in November 2014 in Sydney, Australia (Figure 1 and 2). This once-in-a-decade event is the flagship global forum on protected areas and the conservation of nature. For seven days, Sydney Olympic Park was teeming with over 6000 park rangers, conservation scientists, politicians, government officials, business people and concerned citizens from 170 countries. They came together to share their experience and ideas about the challenges and opportunities facing the global protected area network.

The breadth of issues addressed at the congress was impressive. Each day was structured around eight themes: Reaching Conservation Goals; Responding to Climate Change; Improving Health and Well-Being; Supporting Human Life; Reconciling Development Challenges; Enhancing Diversity and Quality of Governance; Respecting Indigenous and Traditional Knowledge and Culture; and Inspiring a New Generation. These different themes involved discussions that spanned all scales of activity, from removal techniques for individual invasive species to updates on international legal frameworks.

Given this overwhelming amount of content, it was not possible for one individual to engage in all the workshops, dialogues and plenaries the conference had on offer. This article is a reflection of the sessions that were attended by the author and how they were relevant to the catchphrase of the congress: 'Parks, people, planet: inspiring solutions'.

\section{Parks}

Preserving natural ecosystems in protected areas or parks is the main international strategy to conserve biodiversity. Sustained efforts to increase the coverage of legally recognised protected areas have resulted in significant gains in recent years. The United Nations Environment Programme Protected Planet Report 2014, which was released at the congress, outlined that, since 2010, 6.1 million $\mathrm{km}^{2}$ of new protected areas have been created. This is close to the size of the entire Australian continent and means that we are on track to meet Target 11 of the Convention on Biological Diversity Aichi Biodiversity Targets, which aims for $17 \%$ of terrestrial and inland water areas to be managed for conservation by 2020 .

Though encouraging, this increase in protected area coverage is yet to halt global biodiversity loss. Species decline and rates of extinction continue to accelerate. According to the Convention on Biological Diversity's Global Biodiversity Outlook 4, published in 2014, this may in part be due to time lags in environmental responses to increased conservation activity. However, this disconnect is rooted in broader pressures including habitat destruction, pollution, climate change, over-exploitation and invasion by exotic species. Much more needs to be done to reduce and counteract these pressures inside and outside formal protected areas if global biodiversity loss is to be arrested. A major focus of the congress was identifying new and adaptive methods to enhance conservation outcomes in light of these pressures.

One of the discussions focused on linking natural assets with the 'real economy' as a way to prevent further degradation and generate the funds required to scale up conservation efforts. Achim Steiner, Executive Director of the United Nations Environment Programme, stressed the importance of conservationists becoming economically literate by using the concept of 'natural capital' and putting a price on the value of ecosystem services. Members of the finance and business community spoke about trends in this direction, through continued development of markets for environmental goods such as carbon and biodiversity. The move towards integrating natural capital could help address the fundamental problem of environmental externalities in the current economic system and generate funds for conservation through payment for ecosystem services. 


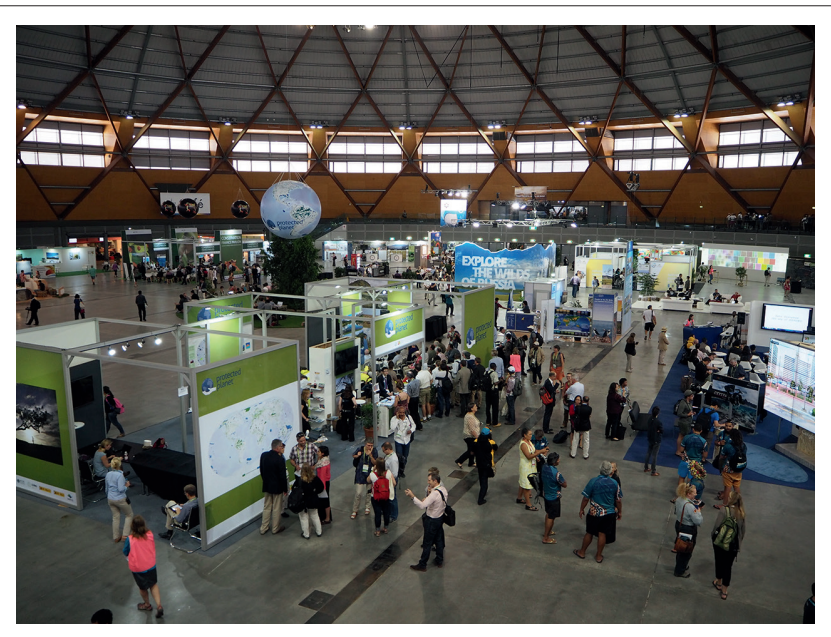

Source: Photograph taken by Ishbel Cullen

FIGURE 1: Pavilions established at the International Union for Conservation of Nature World Parks Congress 2014.

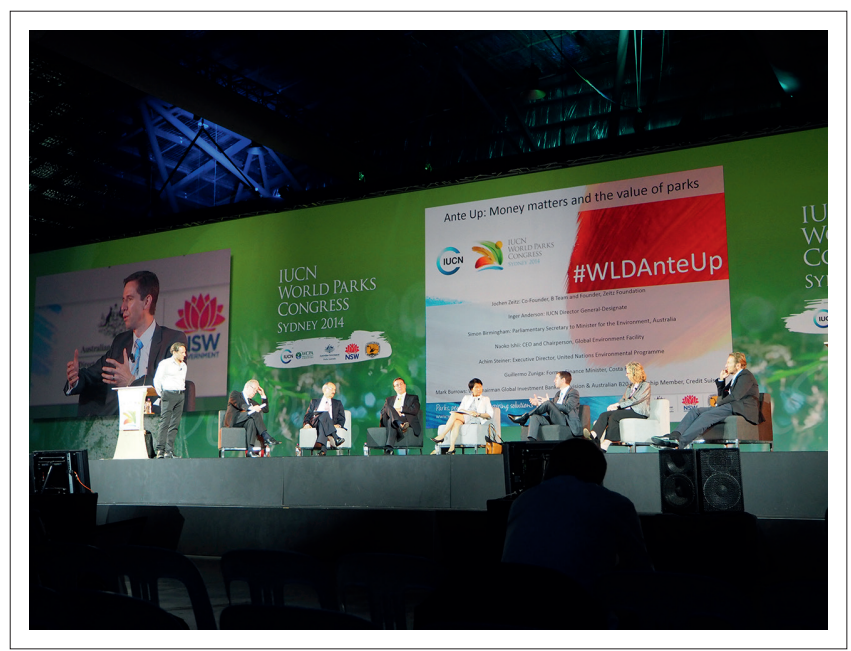

Source: Photograph taken by Ishbel Cullen

FIGURE 2: Leaders of Pacific Island nations make a commitment to expand marine protected areas at the International Union for Conservation of Nature World Parks Congress 2014.

Representatives from the World Wide Fund for Nature and Credit Suisse presented their 2014 report on conservation finance at the congress, showing that investment in biodiversity conservation needs to be around $\$ 200-\$ 300$ billion globally per year to adequately protect the world's most important ecosystems. While this figure is $20-30$ times the current rate of investment, it represents only $1 \%$ of the total private sector's annual investment on a global scale. The speakers argued for increased involvement by the private sector in order to complement existing conservation finance from public and philanthropic channels. This will require creating opportunities for conservation activities that can generate returns for investors as well as protect biodiversity.

\section{People}

The contribution of protected areas to human well-being was widely acknowledged at the congress, with many sessions relating to the physical, psychological and cultural benefits of parks and how these interactions can be used to realise positive outcomes for conservation as well as human populations.

The opportunities for indigenous peoples to achieve economic, social and cultural benefits through the management of protected areas was another area of focus, with a strong representation of indigenous communities at the congress. There are many relevant examples from Australia, where there are 51 declared indigenous protected areas covering over 36 million hectares. For instance, managing fire regimes in the Savannah Country of the Northern Territory has resulted in carbon credits that the traditional owners can sell to generate revenue. Monitoring wildlife and removing marine debris has provided opportunities for employment for many indigenous peoples in the sea country of North Queensland. These examples demonstrate the potential synergies and co-benefits of biodiversity conservation management.

A recent IUCN report, Urban Protected Areas: Profiles and best practice guidelines (2014), was presented by lead author Dr Ted Trzyna. He explained that urban protected areas are accessible to a large number of visitors from diverse backgrounds and therefore play an important political role in building urban constituencies that value conservation.

By researching urban protected areas around the world, Dr Trzyna and his team have collected a number of important observations and lessons. Not surprisingly, urban areas face the most pressure from development, pollution and high levels of use. However, there are also many positive reports. In Hong Kong, a remarkable $40 \%$ of land is in protected parklands. In Taipei, Yangmingshan National Park has an extraordinary volunteering culture, with over 700000 hours of volunteer work dedicated per year. In San Francisco, the Parks Conservancy, a nonprofit organisation, collaborates with the Golden Gate National Parks to deliver extensive education programmes, with a focus on climate change education. Instead of talking about climate change politics or predictions, they are highlighting changes currently occurring in the park to make climate change real and accessible.

Whilst there are important opportunities for mutually beneficial outcomes for both human populations and biodiversity conservation, in many contexts exploitation and degradation remain dominant. As with most discussions on natural resource management, at the congress notions of balancing resource use and resource preservation were ubiquitous.

A pragmatic approach to achieving conservation outcomes often involves a compromise. However, 'balancing' terminology is frequently used to give the impression of measured consideration, but in reality it is used to justify poor environmental outcomes. With many politicians and representatives from extractive industries present at the congress, it was important to question how decisions were balanced, by whom and according to what assumptions. 


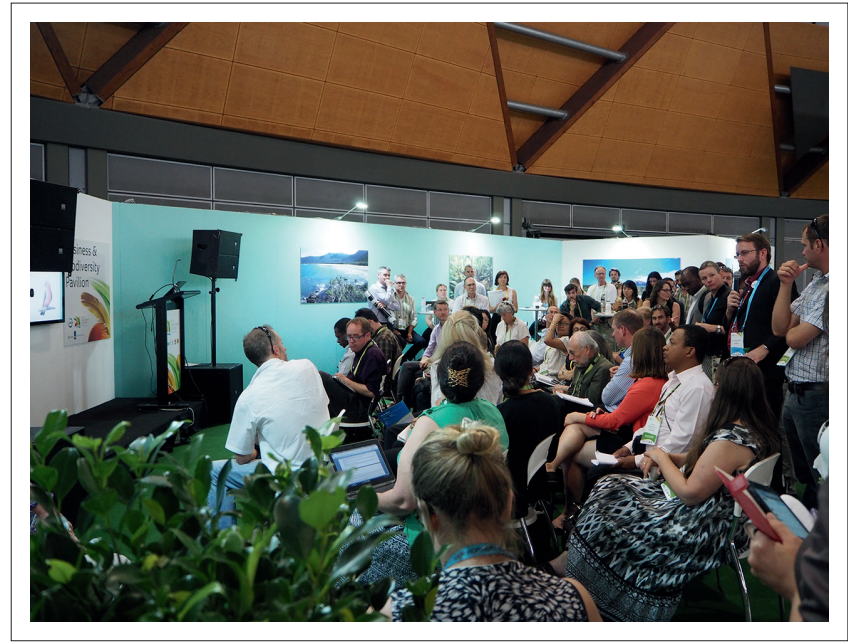

Source: Photograph taken by Ishbel Cullen

FIGURE 3: Congress delegates discuss biodiversity offsets and their application in different countries.

This was clearly demonstrated in a session discussing biodiversity offset policies (Figure 3). In some contexts biodiversity offsets do represent an opportunity to balance human needs and achieve positive outcomes for biodiversity. For example, where the status quo would see continued degradation and loss of habitat, offsetting provides opportunities for net biodiversity benefits. However, biodiversity offsets can be misused, resulting in a net loss of protected habitat. For example, one speaker identified the potential for biodiversity offsets to resource existing commitments to protected areas, which runs counter to the principle of additionality.

The emphasis at the congress on integrating human needs and biodiversity conservation was progressive, and accurately represented current realities. However, some cases lacked caution and neglected the importance of 'no-go' areas exclusively dedicated to the conservation of nature.

\section{Planet}

While most direct threats to biodiversity occur at a local scale, the ultimate affliction on nature is now occurring on a global scale, with continued global warming threatening climate stability. This overwhelming problem, with its varied and pervasive impacts, will likely define the coming century for humanity as well as the managers of biodiversity conservation.

At the congress there was a climate change stream; however, given its universal effects, it needed to be integrated into all areas of discussion. This separation reflects the genuine challenge of reconciling the temporal and spatial scales of climate change in planning and management today. The challenge for all conservationists is how to focus on immediate and local conservation goals whilst considering, and acting upon, the bigger-picture issues.
Whilst maintaining this perspective is difficult, it is essential, given the devastating effect unabated climate change will have on biodiversity, but also the increased strategic importance of protected areas in a warming world. Many of the presenters who addressed the issue of climate change spoke about the role protected areas will play in adaptation through increasing resilience to environmental extremes. For example, representatives of the IUCN from the Pacific Islands explained the potential for ecosystem-based adaptation to sea level rise by planting mangroves to buffer coastlines against king tides.

The immense opportunities for integrating biodiversity outcomes with greenhouse gas emission mitigation activities were also discussed, especially in relation to the United Nations Reducing Emissions from Deforestation and Forest Degradation projects. However, presenters from participating projects expressed frustration at the lack of demand for carbon credits globally. It is hoped that the shift to a carbonconstrained world will increase demand in carbon markets, with co-benefits for biodiversity conservation.

\section{Conclusion}

The IUCN had a difficult task in organising the 2014 World Parks Congress. It had to be mainstream and inclusive, creating an open forum where politicians and business leaders were included in conversations with dedicated conservationists. It had to confront, in an open and honest manner, the many challenges and the scale of action required. The congress also needed to celebrate significant achievements and progress whilst acknowledging the current biodiversity crisis and our uncertain future.

These different tensions were reflected in the formal conclusion of the congress, 'The Promise of Sydney' (see http:/ / worldparkscongress.org/about/promise_of_sydney. html), which was collaboratively written by congress participants. This representation of the congress outcomes included a vision for the future, a set of innovative approaches and solutions to solve challenges facing protected areas, and commitments made at the congress by countries and organisations. Cynics might say that these outcomes amount to hand waving and rhetoric. We all know that talk is cheap, but human interaction and the sharing of ideas with other individuals is motivating and helps create the global networks required to address global problems.

\section{Acknowledgements Competing interests}

The author declares that she has no financial or personal relationships which may have inappropriately influenced her in writing this article. 